\title{
The influence of hepatitis B virus (HBV) or hepatitis $C$ virus (HCV) infections on the pregnancy course
}

\author{
Julita Nikolajuk-Stasiuk, Tadeusz W. Lapinski® \\ Department of Infectious Diseases and Hepatology, Medical University of Bialystok, Poland
}

\begin{abstract}
Objectives: The incidence of HBV infections among the pregnant in Europe falls within the range of $1-7 \%$, whereas it is $1.7-4.3 \%$ for HCV.

The aim was to assess the course of pregnancy among women infected with $\mathrm{HBV}$ or $\mathrm{HCV}$, and the condition of neonates in the fifth minute after the birth.

Material and methods: The study included 157 pregnant individuals infected with HBV, 53 infected with HCV, and 330 healthy pregnant women. None of the women infected with HBV and HCV as well as from the control group were infected with HIV, and none of them took intoxicants.

Results: Weight of neonates delivered by healthy women was higher as compared with children born by women infected with HBV or HCV (3.517 vs 3.347 and 3.366). The Apgar score of neonates delivered by women with HBV and HCV infections was lower as compared with the children born by healthy women ( 9.4 vs 9.3 vs $9.7 ; p<0.05$ ). Premature births occurred more often in HBV and HCV-infected women than in the control group ( $14.6 \%$ and $24.5 \%$ vs $6.96 \% ; p<0.05$ ). Miscarriages were significantly more common among the patients with HCV infections as compared with the patients who were healthy $(9.4 \%$ vs $1.8 \% ; p<0.05)$. In comparison with the healthy individuals, this group of patients experienced pruritus $(10.5 \%$ vs $4.2 \% ; \mathrm{p}<0.05)$, oedemas ( $9.4 \%$ vs $2.4 \% ; \mathrm{p}<0.05)$, and hypertension $(9.4 \%$ vs $1.5 \% ; \mathrm{p}<0.05)$ more often.

An increase in HBV loads was observed between the $6^{\text {th }}$ and $28^{\text {th }}-32^{\text {nd }}$ week of pregnancy among the infected with HBV, and then, a decrease was observed in the $6^{\text {th }}$ months after the delivery.

Conclusions: The women infected with $\mathrm{HBV}$ without $\mathrm{HBsAg}(-)$ and the infected with $\mathrm{HCV}$ are subject to common incidence of premature births. Women infected with HCV often experience oedemas, hypertension, and pruritus.
\end{abstract}

Key words: HBV or HCV infection in pregnancy; childbirth

Ginekologia Polska 2021; 92, 1: 30-34

\section{INTRODUCTION}

The incidence of hepatitis B virus (HBV) infections in the pregnant women throughout Europe ranges from 1\% to 7\% [1]. Pregnant women are usually aware of the HBV infections; less often they learn about the infection upon examination performed during initial stages of the pregnancy. Neonates delivered by women infected with HBV become infected in less than $1 \%$ of cases in Europe [2]. The likelihood of a neonate becoming infected in a perinatal or postnatal way does not exceed $10 \%$ due to widely applied active and passive prophylaxis of children delivered by HBV-infected women [a vaccine and a hepatitis B immunoglobulin (HBIG) specific serum administered within 12 hours after the delivery] $[3,4]$. It is possible for a child to become infected via an intrauterine way. Also, a child may become infected by an HBV-infected woman who has high HBV viraemia (> 200,000 IU/mL) or high surface antigen of the hepatitis B virus (HBsAg) concentration (> 4-4.5 $\log _{10} \mathrm{IU} / \mathrm{mL}$ ) [3].
The risk of such an infection regards most often the women with HBV viraemia above $6 \log _{10} 1 \mathrm{IU} / \mathrm{mL}$ and hepatitis $B$ envelope antygen ( $\mathrm{HBeAg})(+)$ presence. The likelihood of an infection with the virus increases proportionally to the viraemia increase $[4,5]$. The devised guidelines present the ways of dealing with women infected with HBV that want to become pregnant (Tab. 1).

Antiviral drugs used in the pregnant infected with HBV decrease the risk of infecting the foetus, however, none of the currently used nucleoside/nucleotide analogues (NAs) are listed as category $\mathrm{A}$ according to Food and Drug Administration (FDA), and thus, their use in pregnant women should be done cautiously. European [European Association for the Study of the Liver (EASL)] and American [American Association for the Study of Liver Diseases (AASLD)] guidelines allow for administering Tenofovir Disoproxil Fumarate (TDF) between the $24^{\text {th }}$ and $32^{\text {nd }}$ week of pregnancy 
Table 1. Guidelines regarding the ways of dealing with pregnant women infected with $\mathrm{HBV}[3,6]$

\section{$1^{\text {st }}$ trimester of the pregnancy - a test for HBsAg presence is recommended; in case of $\mathrm{HBsAg}(+)$ - viraemia assessment}

There is no indication to start the therapy for women without advanced fibrosis

Women with advanced fibrosis or cirrhosis - TDF therapy is recommended

The pregnant with high DNA HBV concentration $(>200,000 \mathrm{IU} / \mathrm{mL}$ ) or $\mathrm{HBsAg}\left(>4 \log _{10} \mathrm{IU} / \mathrm{mL}\right.$ ) should received TDF in $24^{\text {th }}-28^{\text {th }}$ week of the pregnancy. It is recommended to discontinue the drug 12 weeks after the delivery

Pregnant women that are treated with NA should continue the TDF therapy; in case of ETV or another NA treatment, the drug should be changed to TDF

Breastfeeding is not contraindicated for women infected with HBV that are not and are treated with TDF

HBsAG — surface antigen of the hepatitis B virus; HBeAG — hepatitis B envelope antygen; TDF - Tenofovir Disoproxil Fumarate; HBV — hepatitis B virus; ETV — Entecavir; NA — Nucleoside/Nucleotide Analogues

in special cases. The drug is used in order to decrease the risk of infecting the foetus.

The probability of a newborn being infected by an hepatitis $\mathrm{C}$ virus (HCV)-infected mother ranges from $1.7 \%$ to $4.3 \%$. It is the highest among the women that are infected with HCV/ Human immunodeficiency viruses (HIV) (19.4\%) and among individuals that take intravenous intoxicants (and who are not HIV-infected; 8.6\%) [7]. The risk of infecting a neonate and a negative influence on the clinical pregnancy course of patients infected with HCV were the basis for EASL and AASLD guidelines for antiviral treatment for all women at procreative age "in the first place" (especially the ones who wanted to become pregnant) [8]. Limited studies on DAA efficacy and adverse reactions among the HCV-infected patients indicate a decreased likelihood of infecting a neonate among the patients that take such antiviral drugs. Although these drugs have not been approved to be used in pregnant women yet, about $60 \%$ of women infected with HCV and pregnant declare that they are eager to use them in order to avoid infecting the child [9].

Despite specified procedures that concern dealing with the patients infected with HBV and HCV, observations regarding the influence of these viruses on the course of pregnancy are ambiguous.

\section{Aim of the work}

The aim of the work was to perform a clinical assessment of the pregnancy course among women infected with HBV or HCV. The following was determined: type of delivery, neonates' condition in the fifth minute after the delivery, weight at birth, and sex. All patients had their biological pa- rameters of liver function monitored. The patients infected with HBV had viraemia monitored throughout the course of pregnancy and after the delivery. HCV-infected patients had the virus genotype and initial viraemia assessed.

\section{MATERIAL AND METHODS}

The study included 157 pregnant women infected with HBV aged from 21 to 42 (mean age: $29 \mathrm{y} / 0$ ), and 53 pregnant women infected with HCV aged from 19 to 46 (mean age: $28 \mathrm{y} / \mathrm{o}$ ). Three hundred and thirty healthy pregnant women aged from 18 to 40 (mean age: $28 \mathrm{y} / 0$ ), who lived in the same region as the infected women, constituted a control group.

None of the women infected with HBV and HCV as well as from the control group was HIV-infected and none of them took intoxicants.

Qualification criteria for HBV-infected women included no $\mathrm{HBeAg}$ and exclusion of cirrhosis. None of the women infected with HBV had been qualified for the treatment earlier nor had been treated with antiviral drugs. The following was monitored among the HBV-infected women: viraemia, ALT activity, serum ALP within the first six weeks of pregnancy, between the $28^{\text {th }}$ and $32^{\text {nd }}$ week of pregnancy and six months after the delivery. In the group of the pregnant infected with HCV, viraemia and virus genotype were determined in the fifth week of pregnancy, whereas ALP and ALT activity was determined in the first six weeks of pregnancy, between $28^{\text {th }}$ and $32^{\text {nd }}$ week of pregnancy, and six months after the delivery.

Neonates had their clinical condition assessed in the fifth month of life by means of Apgar score.

All patients had serum $\mathrm{HBsAg}, \mathrm{HBeAg}$, anti-HBe, and anti-HCV antibodies assessed once by means of MEIA (microparticle enzyme immunoassay) and using Abbott tests (Germany).

HBV-DNA quantity was determined by RT-PCR using sets of COBAS AmpliPre/COBAS TagMan HBV Test, version 2.0 produced by ROCHE. The sensitivity amounted to $9 \mathrm{IU} / \mathrm{mL}$, whereas linearity was $20 \mathrm{IU} / \mathrm{mL}$.

Among women with positive anti-HCV, quantitative assessment and genotype were determined by RT-PCR method and using sets of COBAS HCV Test, version 2.0 produced by ROCHE (Germany).

The patients provided their informed consent to participate in the study according to the protocol accepted by the Bioethical Committee of Medical University in Bialystok (R-I-002/134/2019).

Statistical analysis of data was conducted by using STATISTICA.PL produced by StatSoft for Windows 10 operating system. The study used Mann-Whitney U test, Spearman's rho, student's t-test, and chi-squared test ( $x 2)$. The level of significance was set at $p<0.05$. 


\section{RESULTS}

Mean pregnancy duration in HBV- and HCV-infected as well as among the healthy patients was similar and amounted to 38-39 weeks. The frequency of spontaneous labour was comparable and amounted to $52 \%$ for HBV patients, $42 \%$ for HCV patients, and $58 \%$ in the control group.

Weight of children delivered by healthy women was higher as compared with children delivered by HBV- or HCV-infected females (3.517 vs 3.347 vs 3.366). In case of HBV-infected women, the weight was significantly lower as compared with the healthy women (Fig. 1).

Having assessed the Apgar score at the fifth minute of life, neonates of HBV- and HCV-infected women showed lower scores as compared with children born to healthy females (9.4 vs. 9.3 vs 9.7; $p<0.05$ ), (Fig. 2).

Premature births occurred significantly more often in the HBV- and HCV-infected as compared with the control group (6.96\% vs $14.6 \%$ and $24.5 \%$; $<0.05)$. In the group of HCV patients, miscarriages were significantly more common as compared with the healthy patients ( $9.4 \%$ vs $1.8 \%$; $\mathrm{p}<0.05$ ). Among the HBV-patients, miscarriages were more frequent than in the control group, however, it was not statistically significant (Tab. 2).

Nausea was the most observed adverse reaction in all the pregnant women. HCV-patients significantly more often experienced pruritus ( $10.5 \%$ vs $4.2 \% ; \mathrm{p}<0.05$ ), oedemas (9.4\% vs $2.4 \% ; p<0.05)$, and arterial hypertension ( $9.4 \%$ vs $1.5 \% ; p<0.05$ ) as compared with the healthy patients (Tab. 3).

Among the HBV-patients, an increase in viraemia between the $6^{\text {th }}$ and $28^{\text {th }}-32^{\text {nd }}$ week of pregnancy was confirmed in $46 \%$ of patients, a decrease in $15 \%$ of patients, and in $39 \%$ of cases there were no changes. In $90 \%$ of patients without detectable viraemia, in the sixth week of pregnancy, its increase was not confirmed between the $28^{\text {th }}$ and $32^{\text {nd }}$ week of pregnancy.

Among the HBV-patients, an increase in viraemia was observed between the $6^{\text {th }}$ and $28^{\text {th }}-32^{\text {nd }}$ week of pregnancy.

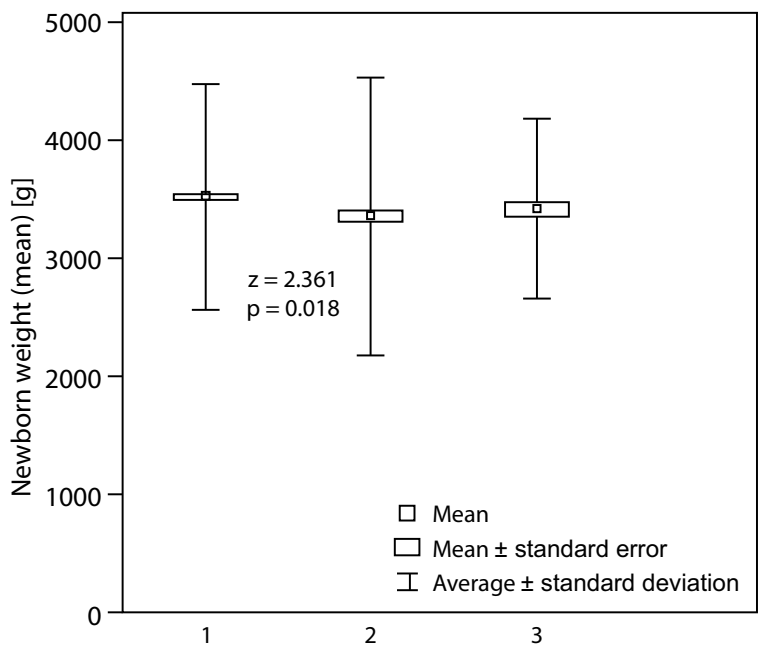

Figure 1. Neonatal weight (mean) among the examined patients and the control group; 1 - pregnant women healthy; 2 - pregnant women infected with hepatitis B virus (HBV); 3 - pregnant women infected with hepatitis $\mathrm{C}$ virus (HCV)

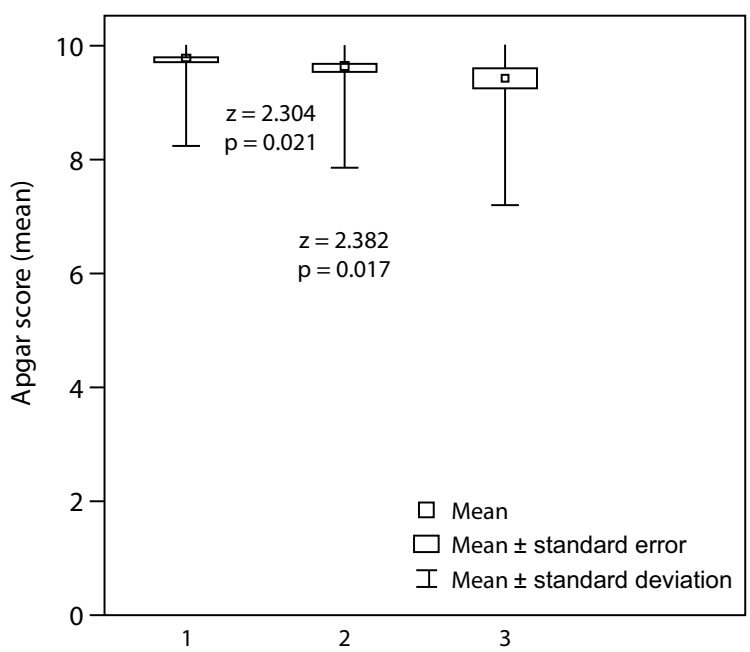

Figure 2. Neonatal scores (mean) on the APGAR scale (5 minutes) obtained in the examined groups of newborns; 1 - pregnant women healthy; 2 - pregnant women infected with hepatitis B virus (HBV); 3 - pregnant women infected with hepatitis $C$ virus (HCV)

\begin{tabular}{|c|c|c|c|}
\hline & \multirow{2}{*}{ pregnant healthy } & \multicolumn{2}{|l|}{ pregnant infected } \\
\hline & & HBV & HCV \\
\hline$n$ & 330 & 157 & 53 \\
\hline Age, average in years (from ... to) & $28 ;(18-41)$ & $29 ;(21-42)$ & $29 ;(20-46)$ \\
\hline Date of delivery, week (from ... to) & $39 ;(36-42)$ & $38 ;(28-42)$ & $38 ;(30-41)$ \\
\hline Premature delivery, n (\%) & $23(6.96 \%)^{1.2}$ & $20(14.6 \%)^{1}$ & $13(24.5 \%)^{2}$ \\
\hline Miscarriage & $6(1.8 \%)^{1}$ & $6(3.8 \%)$ & $5(9.4 \%)^{1}$ \\
\hline Perinatal death & 1 & 0 & 0 \\
\hline Childbirth through the ways of nature & $194(59 \%)$ & $82(52 \%)$ & $22(42 \%)$ \\
\hline Child's sex $+/ \widehat{\jmath}$ & 174/156; (53\%/47\%) & $73 / 84 ;(46 \% / 54 \%)$ & $29 / 24 ;(55 \% / 45 \%)$ \\
\hline Birth weight of a child [g] & 3517 & 3347 & 3366 \\
\hline Appgar scoring in 5 minutes & 9.7 & 9.4 & 9.3 \\
\hline
\end{tabular}




\begin{tabular}{|c|c|c|c|}
\hline \multirow{2}{*}{ Symptoms } & \multirow{2}{*}{$\begin{array}{l}\text { pregnant } \\
\text { healthy }\end{array}$} & \multicolumn{2}{|c|}{ pregnant infected } \\
\hline & & HBV & HCV \\
\hline$n$ & 330 & 157 & 53 \\
\hline Nausea, n (\%) & $20(6.1 \%)$ & $10(6.4 \%)$ & $2(3.8 \%)$ \\
\hline Edema, $n(\%)$ & $8(2.4 \%)^{*}$ & $8(5.1 \%)$ & $5(9.4 \%)^{*}$ \\
\hline Hypertension, n (\%) & $5(1.5 \%)^{*}$ & $6(3.8 \%)$ & $5(9.4 \%)^{*}$ \\
\hline Diabetes, n (\%) & $4(1.2 \%)$ & $3(1.9 \%)$ & $2(3.8 \%)$ \\
\hline Urinary tract infection, $\mathrm{n}(\%)$ & $2(0.6 \%)$ & $6(3.8 \%)$ & $1(1.9 \%)$ \\
\hline Itchy skin, n (\%) & $14(4.2 \%)^{*}$ & $11(7.0 \%)$ & $6(10.5 \%)^{*}$ \\
\hline Anemia, n (\%) & 0 & $4(2.5 \%)$ & 0 \\
\hline HELLP syndrome, n (\%) & 0 & 0 & 1 \\
\hline
\end{tabular}

* - statistically significant difference; HBV — hepatitis B virus; $\mathrm{HCV}$ - hepatitis $C$ virus

The highest increase was confirmed among the pregnant with initial viraemia of HBV DNA $\leq 4 \log _{10} \mathrm{IU} / \mathrm{mL}$ in the $6^{\text {th }}$ week of pregnancy.

In four HBV-patients, who experienced a miscarriage, $\mathrm{HBV}$ viraemia was at $4 \log _{10} \mathrm{IU} / \mathrm{mL}$, whereas in two it was undetectable.

HCV infections were cased in $67 \%$ of patients by $1 \mathrm{~b}$ genotype, in $20 \%-3 \mathrm{a}$, and in $13 \%-4$ genotype.

An influence of HCV RNA viraemia on possible clinical symptoms in the pregnant females was not observed.

In HBV- and HCV-patients, a mean ALT and ALP activity during the pregnancy did not change and remained within normal limits.

There were no cases of infecting a neonate both regarding HBV and HCV.

\section{DISCUSSION}

Patients with chronic HBV infections in Europe and the US are usually characterized by the lack of HBeAg. The situation is different in Asia, and it may exert a significant influence on the course of this infection among the pregnant.

$\mathrm{HBV}$ and HCV infections influence an increased activity of proinflammatory cytokines: IL-2, IL-6, IL-10, macrophage migration inhibitory factor (MIF), and TNF-a. In pregnant women they may cause an increase in the percentage of miscarriages, premature births, and a worse clinical condition of delivered neonates that is determined by the Apgar score [10]. Cui et al. [5] compared 513 pregnant women that suffered from chronic HBV infections with 20,491 pregnant women without this infection and showed a statistically more frequent occurrence of miscarriages in HBV patients that were pregnant. In the authors' studies, premature births were observed more often in HBV- and HCV patients. However, the frequency of miscarriages was statistically higher among HCV patients as compared with the healthy individuals.

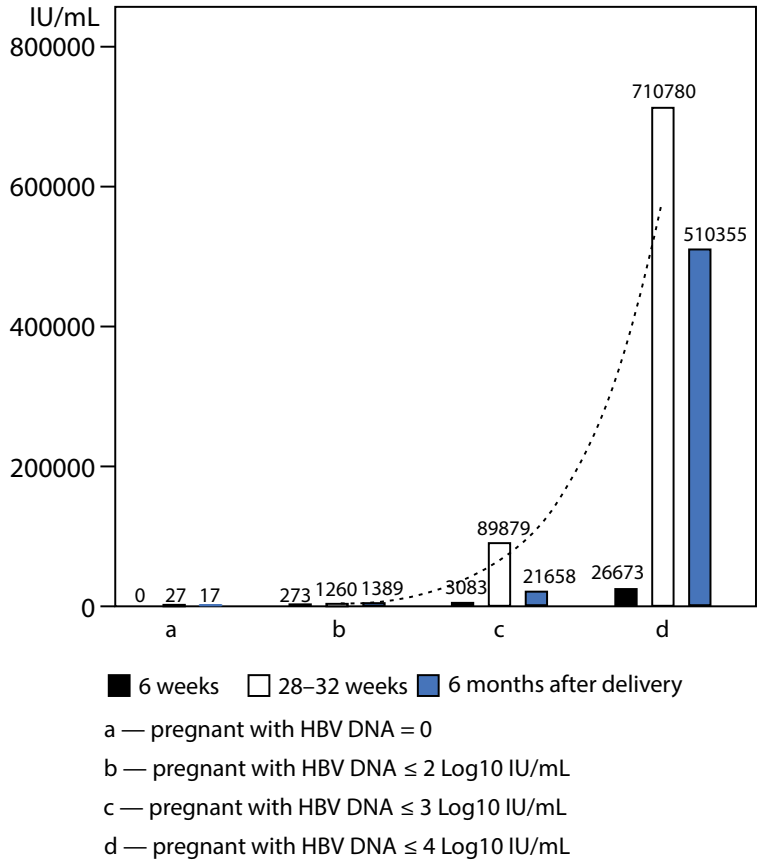

Figure 3. HBV load in serum at 6, 28-32 weeks of pregnancy and 6 months after delivery

Although miscarriages were often observed in HBV patients, there was no statistically significant difference as compared with the healthy females.

During pregnancy, high concentration of adrenal corticosteroids may influence the increase in HBV viraemia $[11,12]$. In most pregnant women with HBV infections and absent $\mathrm{HBeAg}$, viraemia is stable. However, in some patients an increase in HBV-DNA and ALT activity is observed during late pregnancy and in the postnatal period [13]. In the authors'studies, an increase in viraemia was observed at the turn of the $2^{\text {nd }}$ and $3^{\text {rd }}$ trimester, and then, a decrease was observed during the $6^{\text {th }}$ month after the delivery. A significant increase with $2 \log _{10}$ was observed among the patients with HBV-DNA $\leq 4 \log _{10} I \mathrm{I} / \mathrm{mL}$ in the $6^{\text {th }}$ week of pregnancy. In other pregnant females, a worrying increase in viraemia was not confirmed. Occasionally, during the perinatal period a significant $\mathrm{HBV}$ reactivation, and serious liver damage with encephalopathy and hepatic coma may occur [14]. Among such patients, an occurrence of disseminated intravascular coagulation (DIC), hepatorenal syndrome, brain oedema, and bile duct infections were observed. Interestingly, prophylactic administration of NA from the $2^{\text {nd }} / 3^{\text {rd }}$ pregnancy trimester does not decrease the risk of liver failure, although it prevents a child from becoming infected [15]. Miscarriages were observed in six pregnant women infected with HBV. However, in none of them an HBV-DNA viraemia was confirmed to exceed $3 \log _{10} \mathrm{IU} / \mathrm{mL}$.

Having assessed the incidence of adverse events, a more common occurrence of oedemas, hypertension and pruri- 
tus was confirmed in HCV-patients as compared with the healthy ones. Dibba et al. [16] assessed the effects of HCV infections on the pregnant women and showed the role this infection played in occurrence of metabolic disorders of lipid and carbohydrate balance. It may have an influence on hepatic steatosis, appearance on insulin-resistant diabetes, and intensification of atherosclerotic processes. Seldom are clinical consequences of HCV infections regarding the course of pregnancy described. An influence of simultaneous HCV and HIV infections or patients addicted to intoxicants do not constitute a good comparative material. In the authors' studies, a frequent incidence of oedemas, hypertension, and pruritus was confirmed among the $\mathrm{HCV}$ patients. These observations are difficult to explain. A significant difference in the clinical course of the pregnancy between the healthy and HBV-infected women was not confirmed. Cai et al. [17] observed a more common incidence of cholestasis of pregnancy among the HBV-patients. Yet, their studies were conducted on a group of $\mathrm{HBeAg}(+)$ patients, what constitutes a significant difference as compared to the authors' studies.

None of the delivered babies was confirmed to have HBV or HCV infection, as well as congenital defects.

\section{CONCLUSIONS}

Pregnant women infected with $\mathrm{HBV}$ without $\mathrm{HBsAg}$, and $\mathrm{HCV}$-infected females are subject to frequent premature deliveries. An increase in viraemia during the pregnancy with its consequent decrease after the delivery is observed in the pregnant with HBV and without HBeAg. HBV infections do not exert an influence on the clinical pregnancy course, whereas HCV infections may lead to oedemas, arterial hypertension, and pruritus during the pregnancy course.

\section{Conflict of Interest}

The authors declare that there is no conflict of interest.

All authors have met the criteria for authorship and have participated sufficiently in the work to take responsibility for it.

The manuscript has been submitted with the full knowledge and approval of the institutions given as the affiliation of the authors.

\section{Funding}

The authors did not receive any funding to implement the manuscript.

\section{REFERENCES}

1. Jonas MM. Hepatitis B and pregnancy: an underestimated issue. Liver Int. 2009; 29 Suppl 1: 133-139, doi: 10.1111/j.1478-3231.2008.01933.x, indexed in Pubmed: 19207977.

2. Komatsu $\mathrm{H}$, Inui $\mathrm{A}$, Komatsu $\mathrm{H}$, et al. [Long-term history of chronic hepatitis $B$ virus infection in children]. Nihon Rinsho. 2004; 62 Suppl 8(6): 303-308, indexed in Pubmed: 15453335.

3. European Association for the Study of the Liver. Electronic address: easloffice@easloffice.eu, European Association for the Study of the Liver. EASL 2017 Clinical Practice Guidelines on the management of hepatitis B virus infection. J Hepatol. 2017; 67(2): 370-398, doi: 10.1016/j. jhep.2017.03.021, indexed in Pubmed: 28427875.

4. Patton $\mathrm{H}$, Tran TT. Management of hepatitis B during pregnancy. Nat Rev Gastroenterol Hepatol. 2014; 11(7): 402-409, doi: 10.1038/nrgastro.2014.30, indexed in Pubmed: 24686270.

5. Cui AM, Cheng XY, Shao JG, et al. Maternal hepatitis B virus carrier status and pregnancy outcomes: a prospective cohort study. BMC Pregnancy Childbirth. 2016; 16: 87, doi: 10.1186/s12884-016-0884-1, indexed in Pubmed: 27113723.

6. Ayoub WS, Cohen E. Hepatitis B Management in the Pregnant Patient: An Update. J Clin Transl Hepatol. 2016; 4(3): 241-247, doi: 10.14218/JCTH.2016.00014, indexed in Pubmed: 27777892.

7. Floreani A. Hepatitis C and pregnancy. World J Gastroenterol. 2013; 19(40): 6714-6720, doi: 10.3748/wjg.v19.i40.6714, indexed in Pubmed: 24187446.

8. Gowda C, Kennedy S, Glover C, et al. Enhanced identification of maternal hepatitis $C$ virus infection using existing public health surveillance systems. Paediatr Perinat Epidemiol. 2018; 32(4): 401-410, doi: 10.1111/ppe.12481, indexed in Pubmed: 29972246.

9. Kushner T, Cohen J, Tien PC, et al. Evaluating Women's Preferences for Hepatitis C Treatment During Pregnancy. Hepatol Commun. 2018; 2(11): 1306-1310, doi: 10.1002/hep4.1264, indexed in Pubmed: 30411077.

10. Safir A, Levy A, Sikuler E, et al. Maternal hepatitis B virus or hepatitis $C$ virus carrier status as an independent risk factor for adverse perinatal outcome. Liver Int. 2010; 30(5): 765-770, doi: 10.1111/j.1478-3231.201 0.02218.x, indexed in Pubmed: 20214739.

11. He $Q$, Song $X$, Huang $Y$, et al. Dexamethasone Stimulates Hepatitis $B$ Virus (HBV) Replication Through Autophagy. Med Sci Monit. 2018; 24 : 4617-4624, doi: 10.12659/MSM.906250, indexed in Pubmed: 29972684

12. Shimizu I, Kohno N, Tamaki K, et al. Female hepatology: favorable role of estrogen in chronic liver disease with hepatitis B virus infection. World J Gastroenterol. 2007; 13(32): 4295-4305, doi: 10.3748/wjg.v13.i32.4295, indexed in Pubmed: 17708600.

13. Söderström A, Norkrans G, Lindh M. Hepatitis B virus DNA during pregnancy and post partum: aspects on vertical transmission. Scand J Infect Dis. 2003;35(11-12):814-819, doi: 10.1080/00365540310016547, indexed in Pubmed: 14723355.

14. Yang YB, Li XM, Shi ZJ, et al. Pregnant woman with fulminant hepatic failure caused by hepatitis B virus infection: a case report. World J Gastroenterol. 2004; 10(15): 2305-2306, doi: 10.3748/wjg.v10.i15.2305, indexed in Pubmed: 15259091.

15. ter Borg MJ, Leemans WF, de Man RA, et al. Exacerbation of chronic hepatitis B infection after delivery. J Viral Hepat. 2008; 15(1): 37-41, doi: 10.1111/j.1365-2893.2007.00894.x, indexed in Pubmed: 18088243. 